\title{
Synthesize and Characterize Dibutyltin (IV) Oxide Complex by Utilizing New Ligand
}

\author{
Emad Alhaydary and Emad Yousif*
}

Department of Chemistry, College of Science, Al-Nahrain University, Baghdad, Iraq

\begin{tabular}{ll}
\hline \multicolumn{1}{c}{ Article's Information } & \multicolumn{1}{c}{ Abstract } \\
\hline Received: & Herein successfully synthesized new organotin (IV) complex Bu 2 SnOL by \\
06.06 .2021 & reacting sulfamethoxazole drug as a ligand with dibutyltin (IV) oxide. The \\
Accepted: & synthesized complex was fully characterized by Fourier transform infrared, \\
30.08 .2021 & 1proton nuclear magnetic resonance, ${ }^{13}$ carbon nuclear magnetic resonance, ${ }^{119}$ tin \\
Published: & nuclear magnetic resonance and ultraviolet-visible spectroscopies. Field emission \\
$31-12-2021$ & scanning electronic microscopy was also applied to study the surface morphology \\
Keywords: & of synthesized complex. The above techniques have demonstrated that the \\
Di-alkyltin & complex was prepared with high percentage of purity. This type of compound has \\
Organotin (IV) & various applications in medicine and industry. For example, using it as photo- \\
Sulfamethoxazole & stabilizer of different plastic polymers (polyvinyl chloride, polystyrene and \\
Photo-stabilizers & polyvinyl alcohol). \\
\hline DOI: $10.22401 / A N J S .24 .4 .01$ & \\
${ }^{*}$ Corresponding author: emad_yousif@hotmail.com
\end{tabular}

\section{Introduction}

Tin is located in group 14 in a post-transition element in the periodic table and it has same chemical features of neighbor elements germanium and lead within the same group. In addition, it has two oxidation states the most stable one is +2 and the least stable one is +4 . Thus, the electronic configuration of tin is $[\mathrm{Kr}] 4 \mathrm{~d}^{10} 5 \mathrm{~s}^{2} 5 \mathrm{p}^{2}$. Tin isotope $\left({ }^{119} \mathrm{sn}\right)$ can be identify by NMR machine due to it has $1 / 2$ spin [1]. Both oxidation states of tin can react with halides, oxygen, and sulfur to make inorganic compounds. The most famous reaction is tin metal with hydrochloric acid to form tin (II) chloride and release hydrogen gas [2]. Another important reaction is with oxygen when heated the tin up in the air to make tin (IV) dioxide. Tin ${ }^{+2}$ materials have one unbounded pair of electrons and their divalent are mainly depending on the coordination number normally $\mathrm{sp}^{3} \mathrm{~d}$-distorted tetrahedral, $\mathrm{sp}^{2}$-trigonal, and $\mathrm{sp}^{3}$-pyramidal geometry structures [3]. Tin has ability to make covalent bond with carbon atom to form organotin materials, which has a unique property make them quite important in both industrial and medicine applications especially as a photostabilizers of plastic polymers such as Poly (vinyl chloride) PVC [4].

Organotin materials are important part of organometallic field and they consist of metallic tin linked to hydrocarbon groups by covalent bonds. In 1849, $\left(\mathrm{C}_{2} \mathrm{H}_{5}\right)_{2} \mathrm{SnI}_{2}$ (diethyltin diiodide) was the first organotin discovered by Frankland [5,6]. This field was grown quickly in the last century especially after Grignard reaction discovery which exhibits the ability of formation tin carbon covalent bond. Nowadays this field still rich because its huge applications in industry and medicine [7,8]. The most famous organotin compounds are tetrabutyltin, trimethyltin chloride, triphenyltin acetate, triphenyltin chloride and triphenyl hydroxide [9].

Organotin (IV) can easily obtained by oxidizing organotin (II) that is more stable. Organotin (IV) can be designed in different forms depending on the number of organic and anion groups connected to the tin such as monoorganotin, di-, tri- and tetra- compounds [10]. As shown in Figure 1, the proposed geometry structure of organotin materials having molecular formula $\mathrm{X}_{4} \mathrm{Sn}$ (hence $\mathrm{X}$ is an organic unit) for example $\mathrm{Me}_{4} \mathrm{Sn}$ with $\mathrm{sp}^{3}$-tetrahedral coordination. However, with lower electronegative for the bonded ligands to the metallic tin which prefers to coordinate to groups more than four for example $\mathrm{sp}^{3} \mathrm{~d}$ trigonalbipyramidal five-coordination ( $\left.\mathrm{Me}_{3} \mathrm{SnCl} . \mathrm{py}\right)$ and $\mathrm{sp}^{3} \mathrm{~d}^{2}$-octahedral six-coordination $\left(\mathrm{Me}_{2} \mathrm{Sn}(\mathrm{acac})_{2}\right)$ [11]. 


\section{Al-Nahrain Journal of Science}

ANJS, Vol.24 (4), December, 2021, pp. 1-6

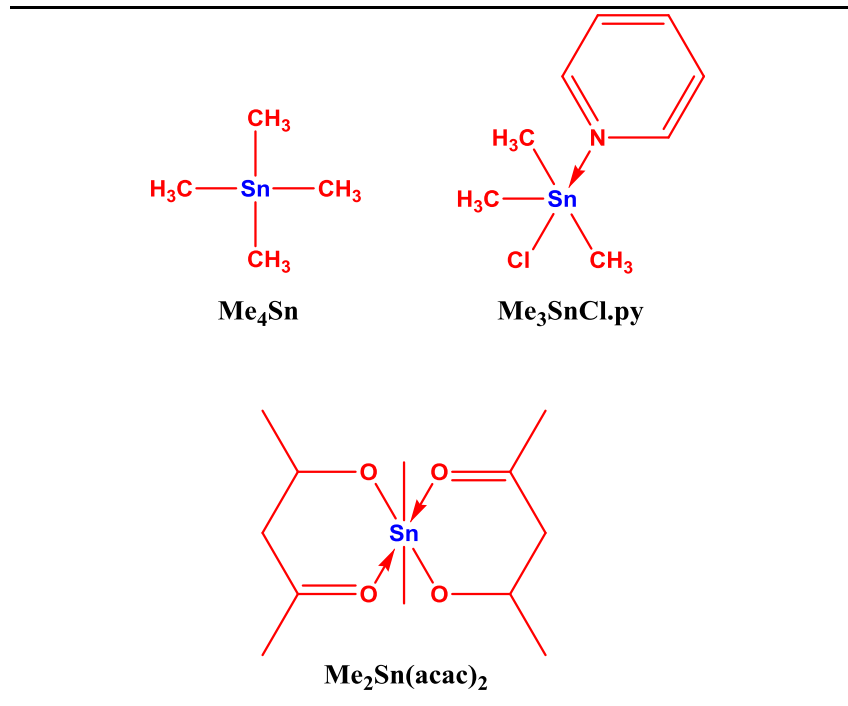

Figure 1. Proposed geometrical structure of organotin compounds with coordination more than four.

There are several applications of organotin materials in both industrial and medicine areas [12-14] and some of these applications and we going to highlight the using of organotin materials as photo-stabilizers of plastic polymers especially the PVC polymeric films [15-19]. Herein we are introducing new organotin photo-stabilizers with using sulfamethoxazole drug as a ligand. Sulfamethoxazole is used as antibiotic against bacterial infections for example $E$. coli and Listeria. Yet nobody has utilized this drug to prepare organotin materials which are suitable for different applications such as PVC photo-stabilizers [20-24].

\section{Chemicals and Procedures}

\subsection{Chemicals}

All reagents and chemicals were uitilized in this project have been got from Fluka, GCC, Sigma Aldrich, BDH, Scharlau, and Romil companies and utilized without any further purification. The IUPAC name of sulfamethoxazole is 4-amino-N-(5-methylisoxazol-3-yl)benzenesulfonamide.

\subsection{Techniques and instruments:}

The FTIR spectra were determined using a modern machine (Bruker Alpha ATR-FTIR) at range between $4000 \mathrm{~cm}^{-1}$ to $400 \mathrm{~cm}^{-1}$ frequency. The proton nuclear magnetic resonance $\left({ }^{1} \mathrm{H}\right.$ NMR) spectra were recorded by using $400 \mathrm{MHz}$ Bruker Avance spectrophotometer. Hence 119-tin nuclear magnetic resonance $\left({ }^{119} \mathrm{Sn}-\mathrm{NMR}\right)$ spectra were determined by utilizing $107 \quad \mathrm{MHz}$ Bruker DRX300NMR spectrophotometer. 13-C nuclear magnetic resonance $\left({ }^{13 \mathrm{C}}\right.$ NMR) spectra were determined by. The tetramethylsilane (TMS) was used as internal standard of measured compounds $(\delta=0.00 \mathrm{ppm})$. Dimethyl sulfoxide (DMSO-d $\left.\mathrm{d}_{6}\right)$ deuterated solvent was used to dissolve the prepared compound. Shimadzu UV-1601 machine was used to record the Ultraviolet and visible spectra for range 200-700 nm and using quartz cell $(1 \mathrm{~cm})$ at ambient temperature for ligand and prepared complexes. Several suitable solvents have been used to dissolve the synthesized compound with very dilute concentration range between 0.6-1 a. u absorption intensity. Flame Atomic Microscopy (FAM) was utilized to study the surface morphology of PVC films by taking twoand three-dimensions images. AA-6880 Shimadzu flame atomic microscopic (Japan) was applied for this study. TESCAN MIRA3 LMU system (Kohoutovice, Czech Republic) was utilized to perform Field Emission Scanning Electron Microscopy (FESEM) field emission scanning electron microscopy and (EDX) energy dispersive X-ray elemental analyses of synthesized complexes using an accelerating voltage $(15 \mathrm{kV})$. However, the morphology measurement of PVC films after irradiation were done using a ZEISS and at accelerating voltage $10 \mathrm{kV}$. Accelerated weather-meter QUV tester (Philips, Saarbücken, Germany) provided by UV-lamp $313 \mathrm{~nm}$ was utilized to expose the PVC films for 300 hours by UV light at room temperature with lambda maximum $313 \mathrm{~nm}$ and $\left(1.052 \times 10^{-8}\right.$ ein. $\mathrm{dm}^{-3} \cdot \mathrm{s}^{-1}$ ) light intensity.

\subsection{Synthesis of di-methyltin (IV) complex}

The Dibutyltin (IV) oxide complex were synthesized by utilizing 1:1 ratio molar percentage of metal:ligand. $0.253 \mathrm{~g}$ $(1.0 \mathrm{mmol})$ of sulfamethoxazole ligand was dissolved in 10 $\mathrm{ml}$ of methanol and left to stir at room temperature until full dissolve. Separately0.3038 $\mathrm{g}(1.0 \mathrm{mmol})$ of $\mathrm{Bu}_{2} \mathrm{SnOCl}$ was dissolved in $5 \mathrm{ml}$ of methanol. The last was added to the stirred sulfamethoxazole mixture and left to stir at reflux for 8 hours. The precipitations were filtered off, washed and dried. Then the crude product was recrystallized from methanol produce pure target product as shown by ${ }^{1} \mathrm{H}$ NMR, ${ }^{13} \mathrm{C}$ NMR, ${ }^{119} \mathrm{Sn}$ NMR and FTIR analysis.

\section{Results and Discussions}

\subsection{Synthesis of organotin (IV) complex:}

The di-organotin complex was synthesized by reacting one to one ratio of metal:ligand. The reactions were done by refluxing the reactants for 8 hours using methanol as a solvent. The crude products were purified by recrystallization from methanol and pure target products were got in very good percentage yield $83 \%$. All products were characterized by ${ }^{1} \mathrm{H}$ NMR, ${ }^{13} \mathrm{C}$ NMR, ${ }^{119} \mathrm{Sn}$ NMR and FTIR analysis to demonstrate the chemical structures of synthesized compound. Scheme 1 shows the reaction scheme of formation di-organotin complex. 


\section{Al-Nahrain Journal of Science}

ANJS, Vol.24 (4), December, 2021, pp. 1-6

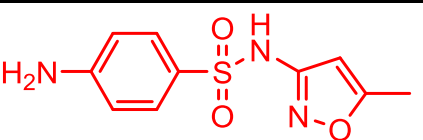

$\mathrm{MeOH}$, reflux, 8 h $\downarrow \mathrm{Bu}_{2} \mathrm{SnOCl}$

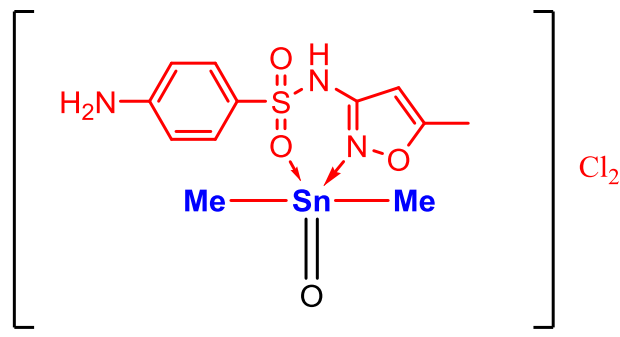

Scheme 1. Synthesis of di-butyltin (IV) oxide complex.

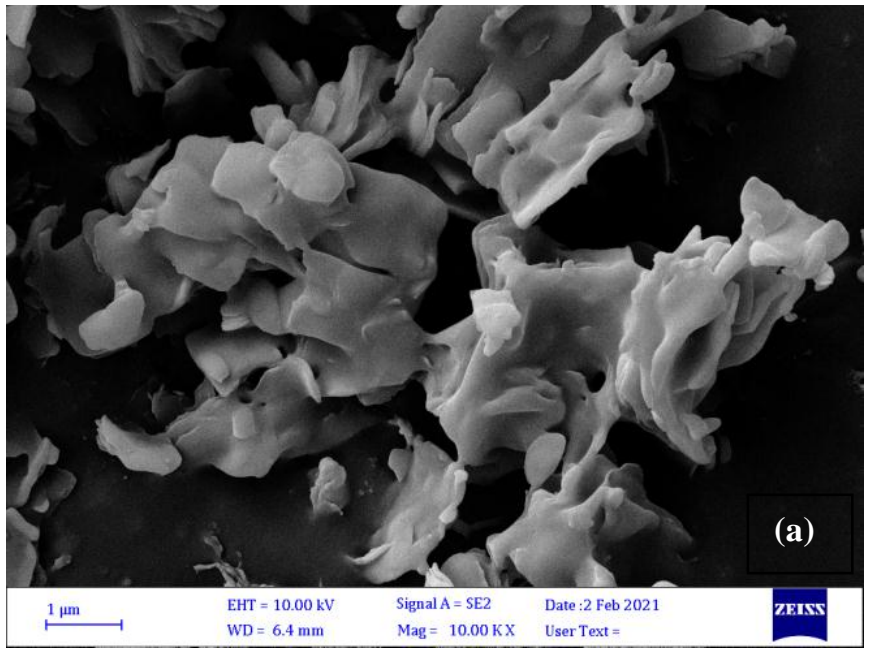

Figure 2. FE-SEM images of $\mathrm{Bu}_{2} \mathrm{SnOL}_{2}$ complex.

Energy dispersive X-ray (EDX) was utilized to provide information about elemental composition of solid surface for synthesized organotin (IV) complexes [25]. To obtain the chemical formula of synthesized material. EDX is linked to field emission scanning electron microscopy (FESEM) and this is a common chemical microanalysis procedure to determine the chemical formula. As shown in Figure 3, the EDX mapping of complex demonstrate the elemental composition of di-butyltin (IV) oxide complex.

\subsection{Characterization of dibutyltin (IV) oxide complexes}

Flame atomic absorption spectrophotometer was used to determine the metal content of complexes. Thus, it has been demonstrated that the experimental results in agreement with theoretical calculations. Thus, the metal percentage demonstrated by Flame atomic absorption is $25.07 \%$ and the theoretical percent is $25.10 \%$.

Field-emission microscopy (FESEM) technique was utilized to exhibit the surface morphology of synthesized complex. Using this approach, it can take microscopic images to the surface of synthesized materials and have an idea about their particles shape and size. This method works by focusing beam electrons and scanning the surface structure to get information about topographic features of complex surface. Furthermore, it can be getting clear, high resolution and less distorted images of examined particles by using FESEM. Figure 2 shows the FESEM images of the surface of synthesized complex as the image show the agglomerated of very small particles in homogenous way.

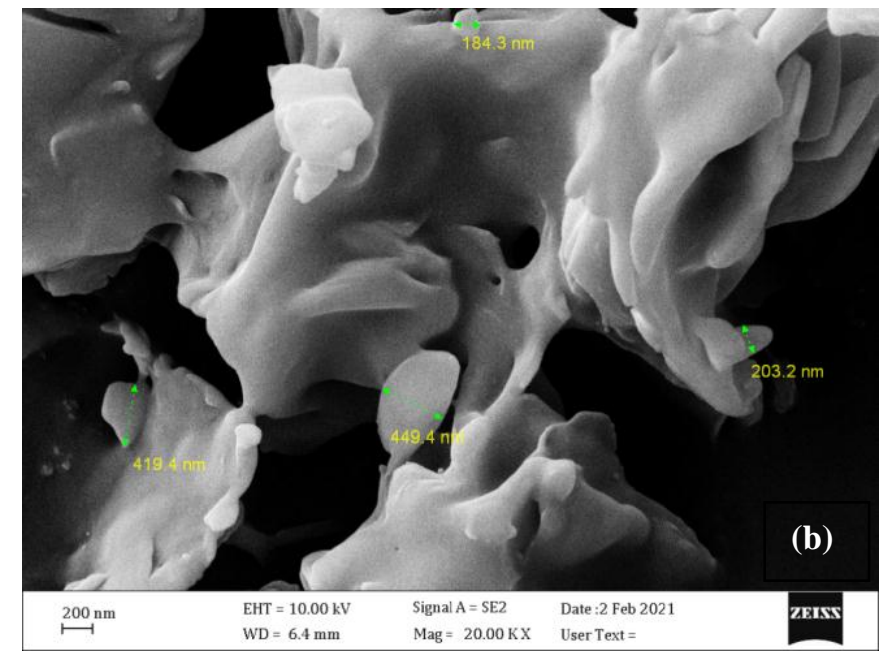

(a) 1 micro magnification. (b) $200 \mathrm{~nm}$ magnification.

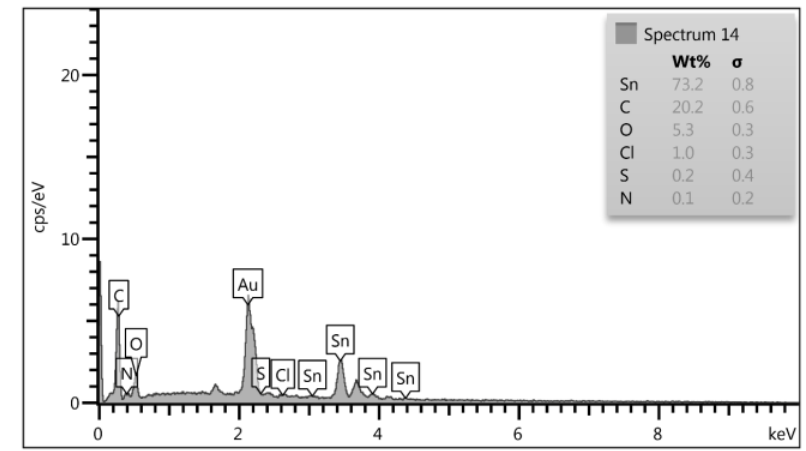

Figure 3. EDX mapping of di-butyltin(IV) oxide complex.

FTIR is considered one of the most important techniques to study the chemical or functional change of chemical structures [26]. Using this approach, it can be identify the formation of new functional groups or breaking existence 


\section{Al-Nahrain Journal of Science}

ANJS, Vol.24 (4), December, 2021, pp. 1-6

functional group which gives clear evidence about the direction of the chemical reaction. Furthermore, FTIR spectrum shows the intensity of functional group absorption peak which give us indication about number of groups within the chemical structure. Di-butyltin (IV) oxide complex was characterized by FTIR and the spectrum showed all required peaks to prove the chemical structure. The most significant peaks to prove the structure of ligand and complex have been summarized in Table 1. As shown in the ligand FTIR spectrum, where $\mathrm{NH}_{2}$ group shows two peaks symmetric and anti-symmetric between $3373 \mathrm{~cm}^{-1}$ and $3473 \mathrm{~cm}^{-1}$ where it is supposed to be. While NH showed peak around $3294 \mathrm{~cm}^{-1}$, Schiff base group $(\mathrm{C}=\mathrm{N})$ around $1501 \mathrm{~cm}^{-1}$ and $\mathrm{SO}_{2}$ two peaks between $1127 \mathrm{~cm}^{-1}$ to 1379 $\mathrm{cm}^{-1}$. Figures 5 shows the FTIR spectra of synthesized complex, where observed shifting in $\mathrm{C}=\mathrm{N}$ and $\mathrm{SO}_{2}$ peaks due to the formation of coordination bonds, $\mathrm{N}-\mathrm{Sn}$ and $\mathrm{O}-$ $\mathrm{Sn}[27]$.

Table 1. FTIR spectroscopic data for ligand and complex.

\begin{tabular}{||c|c|c|c|c||}
\hline \multirow{2}{*}{ Compounds } & \multicolumn{4}{|c|}{ Wave number $\mathbf{~ c m}^{-1}$} \\
\cline { 2 - 5 } & $\mathrm{NH}_{2}$ & $\mathrm{~N}-\mathrm{H}$ & $\mathrm{C}=\mathrm{N}$ & $\mathrm{SO}_{2}$ \\
\hline \hline \multirow{2}{*}{$\mathrm{L}$} & 3463.64 & 3294.91 & 1501 & 1127 \\
& 3372.65 & & & 1337 \\
\hline
\end{tabular}

Proton Nuclear Magnetic Resonance ( $\left.{ }^{1} \mathrm{H}-\mathrm{NMR}\right)$ spectroscopy was also applied to identify the chemical structure of synthesized materials. It considers one of the most important technique to characterize the chemical structure by determining the hydrogen atoms within the compound structure according to their environment [28, 29]. The ${ }^{1} \mathrm{H}-\mathrm{NMR}$ spectra of synthesized complexes show all required peaks to demonstrate the chemical structure of resulting compounds. Thus DMSO- $\mathrm{d}_{6}$ was used as a good solvent to prepare the ${ }^{1} \mathrm{H}-\mathrm{NMR}$ samples. As shown in the ${ }^{1} \mathrm{H}-\mathrm{NMR}$ spectrum of ligand, where showed broad singlet peak that resonate at $11.07 \mathrm{ppm}$ due to the exchange proton of $\mathrm{NH}$ group. They also show all the aromatic protons with the expected multiplicity and chemical shifts. It has also showed a multiple peak at 6.23-6.19 ppm which is related to hetro-aromatic hydrogen close to higher electronegative atoms (nitrogen, and oxygen) which causes de-shielding of the proton.

${ }^{1} \mathrm{H}$ NMR spectrum of synthesized compound shows clearly reveal the shift of $\mathrm{NH}$ group signal value toward 3.5 ppm. All ${ }^{1} \mathrm{H}$ NMR data have been summarized in Table 2. For $\mathrm{Bu}_{2} \mathrm{SnOL}$ complex the spectrum shows extra peaks at $1.3 \mathrm{ppm}$ and $0.9 \mathrm{ppm}$ for butyl groups linked to tin with ratio 1:2 ligand to alkyl groups and that's clear evidence that one unit of ligand linked to tin.
Table 2. ${ }^{1} \mathrm{H}-\mathrm{NMR}$ spectral data for ligand and metal complexes.

\begin{tabular}{|c|c|}
\hline Compound & $\begin{array}{c}{ }^{1} \mathrm{H}-\mathrm{NMR}(400 \mathrm{MHz}: \\
\text { DMSO-d } 6, \delta, \mathrm{ppm}, J \\
\text { in Hz) }\end{array}$ \\
\hline $\mathrm{H}_{2} \mathrm{~N}-$ & $\begin{array}{c}11.07(\mathrm{~s}, \text { exch } 1 \mathrm{H}, \\
\mathrm{NH}), 7.58(\mathrm{~d}, J=8.0 \\
\mathrm{Hz}, 2 \mathrm{H}, \mathrm{Ar}), 6.70(\mathrm{~d}, J \\
=8.0 \mathrm{~Hz}, 2 \mathrm{H}, \mathrm{Ar}), \\
6.23-6.19(\mathrm{~m}, \text { exch } 2 \mathrm{H}, \\
\left.\mathrm{NH}_{2} \text {, and } 1 \mathrm{H}, \mathrm{Ar}\right), 2.41 \\
\quad\left(\mathrm{~s}, 3 \mathrm{H}, \mathrm{CH}_{3}\right) .\end{array}$ \\
\hline$\|_{0}$ & $\begin{array}{c}11.07(\mathrm{~s}, \text { exch } 1 \mathrm{H}, \\
\mathrm{NH}), 7.58(\mathrm{~d}, J=8.0 \\
\mathrm{Hz}, 2 \mathrm{H}, \mathrm{Ar}), 6.70(\mathrm{~d}, J \\
=8.0 \mathrm{~Hz}, 2 \mathrm{H}, \mathrm{Ar}), \\
6.23-6.19(\mathrm{~m}, \text { exch } 2 \mathrm{H}, \\
\left.\mathrm{NH}_{2}, \text { and } 1 \mathrm{H}, \mathrm{Ar}\right), 2.40 \\
\left(\mathrm{~s}, 3 \mathrm{H}, \mathrm{CH}_{3}\right), 1.30(\mathrm{~m}, \\
\left.12 \mathrm{H}, 6 \mathrm{CH}_{2}\right), 0.90(\mathrm{t}, J \\
\left.=6.7,6 \mathrm{H}, 2 \mathrm{CH}_{3}\right) .\end{array}$ \\
\hline
\end{tabular}

The ${ }^{13} \mathrm{C}$ NMR spectra of synthesized complex were analyzed and demonstrated the existence of needed peaks to prove their chemical structures and all data of ${ }^{13} \mathrm{C}$ NMR are summarized in Table 3. The ligand ${ }^{13} \mathrm{C}$ NMR spectrum shows 8 peaks which is related to eight carbon atom environments. One peak at aliphatic region (11.86 ppm) returns to the side $\mathrm{CH}_{3}$ group. While $\mathrm{Bu}_{2} \mathrm{SnOL}$ complex spectrum shows extra four peaks in aliphatic region return to butyl groups linked to tin.

Table 3. ${ }^{1} \mathrm{H}-\mathrm{NMR}$ spectral data for ligand and metal complexes.

\begin{tabular}{|c|c|}
\hline Compound & $\begin{array}{c}\text { 1'H-NMR (400 MHz: } \\
\text { DMSO-d6, } \boldsymbol{\delta}, \mathbf{p p m}, \boldsymbol{J} \text { in } \\
\mathbf{H z})\end{array}$ \\
\hline \hline & $\begin{array}{c}169.74,157.79,153.14, \\
128.67,123.90,112.40, \\
95.12,11.89\end{array}$ \\
\hline & $\begin{array}{c}169.72,157.78,153.13, \\
128.66,123.89,112.39, \\
95.12,27.4,25.3,22.51, \\
14.1,13.80 .\end{array}$ \\
\hline
\end{tabular}

119-Tin nuclear magnetic resonance technique is widely utilized to identify the organotin compounds and also tin inorganic materials in both solid and liquid states. The importance of ${ }^{119} \mathrm{Sn}-\mathrm{NMR}$ spectrum is demonstrating the tin coordination number and also proves the existence of single organotin compound when the spectrum shows only one 


\section{Al-Nahrain Journal of Science}

ANJS, Vol.24 (4), December, 2021, pp. 1-6

sharp singlet peak [30-32]. DMSO-d 6 was used as deuterated solvent to record the ${ }^{119} \mathrm{Sn}-\mathrm{NMR}$ spectra of synthesized complex. The ${ }^{119} \mathrm{Sn}-\mathrm{NMR}$ spectra show peaks at -231.02 for $\mathrm{Bu}_{2} \mathrm{SnOL}$ complex. Hence this is the region of hexa-coordinated organotin (IV) complexes [33-36].

The ultraviolet technique was utilized to characterize the ligand and prepared complexes using DMSO as a polar solvent. The spectrum of synthesized complex shows peak at lambda maximum around $300 \mathrm{~nm}$ which could belongs to $\pi \rightarrow \pi^{*}$ and $n \rightarrow \pi^{*}$ electronic transition but they are overlapped. It does not notice a peak at visible region because Sn (IV) complexes are diamagnetic and there is no d-d transition. The UV adsorption region for all measured compounds were around $270-340 \mathrm{~nm}$ and this makes these aromatic materials very important as photo-stabilizers as will be explained in more details next section.

\section{Conclusion}

To summarize di-organotin (IV) complex was successfully synthesized using sulfamethoxazole drug as a ligand. The chemical structures of new complexes $\left(\mathrm{Bu}_{2} \mathrm{SnOL}\right)$ were demonstrated using various spectroscopic techniques such as Fourier transform infrared, ${ }^{1}$ proton nuclear magnetic resonance, ${ }^{13}$ carbon nuclear magnetic resonance, and ${ }^{119}$ tin nuclear magnetic resonance, ultraviolet-visible spectroscopies. The surface features of complexes have also exhibited by field emission scanning electronic microscopy. In future it is going to use this complex as a photo-stabilizer of various plastic polymers such as polyvinyl chloride and polystyrene.

\section{Acknowledgments}

We would like to thanks Al-Nahrain University their support.

\section{Conflicts of Interest}

The authors declare no conflict of interest.

\section{References}

[1] Davies A. G.; Gielen M.; Pannell K. H. and Tiekink E. R. T.; "Tin Chemistry Fundamentals, Frontiers and Applications", $1^{\text {st }}$ Ed.; John Wiley \& Sons, Ltd.; 5-6, 2008.

[2] Kucklick J. R. and Ellisor M. D.; "A review of organotin contamination in arctic and subarctic regions", Emerg Contam, 5150-156, 2019.

[3] Fadhil Z.; Adil H.; Alsayed R.; Al-Mashhadani M. H.; Jawad A. H.; Ahmed D. S. and Yousif E.; "Poly (Vinyl Chloride) Containing Gynostemma Pentaphyllum as a Photostabilizer", Materials Science Forum, 1021, 251259, 2021.

[4] Watheq B.; Yousif E.; Al-Mashhadani M. H.; Mohammed A.; Ahmed D.S.; Kadhom M. and Jawad A. H. A.; "Surface Morphological Study, Poly (Vinyl Chloride) Photo-Stabilizers Utilizing Ibuprofen Tin Complexes against Ultraviolet Radiation". Surfaces, 3: 579-593, 2020 .
[5] Yang P.; Yan J.; Sun H.; Fan H.; Chen Y.; Wang F. and Bi Shi B.; "Novel Environmentally Sustainable Cardanol-based Plasticizer Covalently Bound to PVC via Click Chemistry: Synthesis and Properties". RSC Adv.; 5: 16980-16985, 2015.

[6] Sakata Y.; Uddin M. A.; Koizumi K. and Murata K.; "Thermal degradation of polyethylene mixed with poly (vinyl chloride) and poly (ethyleneterephthalate)". J. Polym. Degrad. Stab. 53: 111-117, 1996.

[7] Yaseen A.A.; Al-Tikrity E. T.; El-Hiti G.; Ahmed D. S.; Baashen M. A.; Al-Mashhadani M. H. and Yousif E.; "A Process for Carbon Dioxide Capture using Schiff Bases 2 Containing a Trimethoprim Unit". Processes, 9: 707, 2021.

[8] Marcilla A. and Beltra'n M.; "Effect of the plasticizer concentration and heating rate on the thermal decomposition behaviour of PVC plastisols. Kinetic analysis". J. Polym. Degrad. Stab. 53: 1-10, 1998.

[9] Blazso M. and Jakab E.; "Effect of metals, metal oxides, and carboxylates on the thermal decomposition processes of poly (vinyl chloride)". J. Anal. Appl. Pyrol. 49: 125-143, 1999.

[10] Al-Mashhadani M. H.; Thamer H.; Adil H.; Ahmed A.; Ahmed D. S.; Bufaroosha M.; Jawad A. H. and Yousif E.; "Environmental and morphological behavior of polystyrene films containing Schiff base moiety", Materials Today: Proceedings, 42: 2693 2699, 2021.

[11] Ahmed A.; Al-Mashhadani M. H.; Ahmed D. S.; Ahmed A. A.; Yousif E. and Yusop R. M.; "Preparation of Polymeric films containing Schiff base as UV-Absorber with Good Resistance against UVPhotoaging", Biointerface Research in Applied Chemistry, 11: 12743 - 12749, 2021

[12] Ahmed A.; Abdallh M.; Al-Mashhadani M. H.; Ahmed D. S.; Bufaroosha M.; Jawad A. H. and Yousif E.; "Environmental Stability of Poly (Vinyl Chloride) Modified by Schiff's Base under Exposure to UV", Biointerface Research in Applied Chemistry, 11: 13465 - 13473, 2021.

[13] Al-Mashhadani M. H.; Ahmed D. S.; Adil H.; Ahmed A.; Thamer H.; Hamad B. A.; Abdallh M.; Ahmed A.; Bufaroosha M.; Mohammed S. A.; Salih N.; Yusop R. M. and Yousif E.; "A quantitative spectroscopic study of the bleaching phenomena in photo-stabilized formulations containing PVC exposed to outdoor conditions", Materials Today: Proceedings, 42: 26862692, 2021.

[14] Khalaf M.; Fadhil Z.; Al-Mashhadani M. H.; Abdallh M.; Bufaroosha M.; Majeed A.; Salih N. and Yousif E.; "PVC Films Performance Stabilized by Dibutyltin (IV) Complex for Sustainable Environment". Journal of Physics: Conference Series, 1664, 2020.

[15] Mohammed S.A.; Najim L.H.; Al-mashhadani M.H.; Ismael M.; Hamad B.A.; Noaman R.; Ibraheem H.; Ahmed D.S. and Yousif E.; "Morphological and Photodecomposition Rate Constant Study of PVC 


\section{Al-Nahrain Journal of Science}

ANJS, Vol.24 (4), December, 2021, pp. 1-6

Films Doped with Sulfadiazine Tin (IV) Complexes". Science Letters, 14, 88-96, 2020.

[16] Gleeson B.; Claffey J.; Ertler D.; Hogan M.; MüllerBunz H.; Paradisi F.; Wallis D. and Tacke M.; "Novel organotin antibacterial and anticancer drugs", Polyhedron, 273619-3624, 2008.

[17] Kucklick J. R. and Ellisor M. D.; "A review of organotin contamination in arctic and subarctic regions", Emerg Contam, 5150-156, 2019.

[18] Burgess R. H.; "Manufacture and Processing of PVC", Applied Science Publishers, xi-xii, 1982.

[19] Carroll W. F.; Johnson R. W.; Moore S. S. and Paradis R. A.; "Applied Plastics Engineering Handbook", Elsevier, 61-76, 2011.

[20] Titow W. T.; "PVC Technology", $4^{\text {th }}$ Ed.; Elsevier, pp. 207-208, 1984.

[21] Nass L. I. and Heiberger C. A.; "Encyclopedia of PVC", Marcel Dekker, ${ }^{\text {nd }}$ Ed.; 397, 1986.

[22] Akovali G.; "Plastic materials: polyvinyl chloride (PVC)", Woodhead Publishing Limited, 23-53, 2012.

[23] Karayıldırım T.; Yanık J.; Yüksel M.; Sağlam M. and Haussmann M.; "Degradation of PVC containing mixtures in the presence of $\mathrm{HCl}$ fixators", J. Polym. Environ.; 13: 365-379, 2005.

[24] Cadogan D. F. and Howick C. J.; "Plasticizers. In Ullmann's Encyclopedia of Industrial Chemistry", Wiley-VCH: Weinheim, Germany, 2000.

[25] Gao A. X.; Bolt J. D. and Feng A. A.; "Role of titanium dioxide pigments in outdoor weathering of rigid PVC". Plast. Rubber Compos.; 37: 397-402, 2008.

[26] Ahmed D. S.; Ibrahim F. M.; Bufaroosha M.; AlMashhadani M. H.; Jawad A. H.; Yusop R. M.; Salih N.; Mohammed S. A. and Yousif E.; "Polyphosphates as thermal stabilizers for poly (vinyl chloride)", Materials Today: Proceedings, 42: 2680-2685, 2021.

[27] Ahmed A. A.; Al-Mashhadani M. H.; Hashim H.; Ahmed D. S. and Yousif E.; "Morphological, Color Impact and Spectroscopic Studies of New Schiff Base Derived From 1,2,4-Triazole Ring", Prog. Color Colorants Coat.; 14: 27-34, 2021.

[28] Wypych G.; PVC Formulary, $2^{\text {nd }}$ Ed.; Chem. Tec, 1-3, 2015.

[29] Mohamed N. A.; Yassin A. A.; Khalil Kh. D. and Sabaa M. W.; "Organic thermal stabilizers for rigid poly (vinyl chloride) I. Barbituric and thiobarbituric acids", Polym. Degrad. Stab.; 70: 5-10, 2000.

[30] Porta M. and Zumeta, E.; "Implementing the Stockholm treaty on persistent organic pollutants", Occup. Environ. Med.; 59: 651-652, 2002.

[31] Grossman R. F.; "Mixed metal vinyl stabilizer synergism. II: Reactions with zinc replacing cadmium", J. Vinyl Addit. Technol.; 12: 142-145, 1990.

[32] Li D.; Xie L.; Fu M.; Zhang J.; Indrawirawan S.; Zhang Y. and Tang S.; "Synergistic effects of lanthanum-pentaerythritol alkoxide with zinc stearates and with beta-diketone on the thermal stability of poly (vinyl chloride)", Polym. Degd. Stab.; 114: 52-59, 2015.

[33] Fu M.; Li D.; Liu H.; Ai H.; Zhang Y. and Zhang L.; "Synergistic effects of zinc-mannitol alkoxide with calcium/zinc stearates and with $\beta$-diketone on thermal stability of rigid poly (vinyl chloride)", J. Polym. Res.; 23, 13, 2016.

[34] Chai R. D. and Zhang J.; "Synergistic effect of hindered amine light stabilizers/ultraviolet absorbers on the polyvinyl chloride/powder nitrile rubber blends during photodegradation", Polym. Eng. Sci.; 53: 17601769, 2013

[35] Wolf R. and Kaul B. L.; "Plastics, Additives. In Ullmann's Encyclopedia of Industrial Chemistry", Wiley-VCH: Weinheim, Germany, 2000.

[36] Bufaroosha M.; Salih N.; Hadi A. G.; Ahmed D. S.; Al-mashhadani M. H. and Yousif E.; "The Effect of UV Aging on the Structure of PVC in the Presence of Organotin (IV) Compounds", ANJS, 23: 57-61, 2020. 